\title{
Symptom Clusters and Quality of Life in Subjects With COPD
}

\author{
Kyeung Eun Lim RN MSN, Sung Reul Kim RN PhD, Hyun Kyung Kim RN PhD, and \\ So Ri Kim MD PhD
}

\begin{abstract}
BACKGROUND: COPD is one of the most common respiratory diseases. Patients with COPD experience and suffer from various physical and psychological symptoms. We performed this study to identify symptom clusters and the effects on quality of life (QOL) in patients with COPD. METHODS: A total of 130 COPD subjects were recruited from a university hospital in South Korea. Dyspnea, fatigue, depression, anxiety, sleep disturbance, dry mouth, and physical functional status were assessed with structured questionnaires. QOL was measured with the Clinical COPD Questionnaire. Factor analysis and cluster analysis were used to identify symptom clusters based on severity of symptom experiences. RESULTS: Three distinct clusters were identified: a respiratoryfunctional cluster (symptom cluster 1), a mood cluster (symptom cluster 2), and a fatigue-sleep cluster (symptom cluster 3). Symptom cluster 1 consisted of dyspnea, physical functional status, and dry mouth; symptom cluster 2 consisted of anxiety and depression; and symptom cluster 3 consisted of sleep disturbance and fatigue. Subgroup cluster analysis showed that COPD subjects with higher-scoring symptoms in symptom clusters 1,2 , and 3 had significantly poorer QOL. The symptom clusters were significantly different depending on age, educational level, and monthly income. CONCLUSIONS: COPD subjects may have specific patterns of symptom clusters. The symptom clusters are related with clinical characteristics and had a negative impact on QOL. To enhance symptom management and QOL, approaches and interventions based on symptom clusters, rather than independent intervention for each symptom, may be more effective. Understanding COPD symptom clusters may help successful symptom management, which can improve QOL for COPD patients. Key words: chronic obstructive pulmonary disease; symptom assessment; symptom cluster; quality of life; factor analysis; cluster analysis. [Respir Care 2017;62(9):1203-1211. () 2017 Daedalus Enterprises]
\end{abstract}

\section{Introduction}

COPD is the most common lower respiratory disease and has become the third leading cause of death worldwide (http://www.who.int/respiratory/copd/burden/en, Accessed November 2, 2016). The prevalence of COPD increases from $3.2 \%$ among adults $18-44$ y old to $11.6 \%$

\footnotetext{
Kyeung Eun Lim is affiliated with the College of Nursing, Korea University, Seoul, Republic of Korea. Sung Reul Kim and Hyun Kyung Kim are affiliated with the College of Nursing, Research Institute of Nursing Science, Chonbuk National University, Jeonju, Repblic of Korea. Dr So Ri Kim is affiliated with the Department of Internal Medicine, Research Center for Pulmonary Disorders, Chonbuk National University Medical School, Research Institute of Clinical Medicine of Chonbuk National University-Biomedical Research Institute of Chonbuk National University Hospital, Jeonju, Republic of Korea.
}

The authors have disclosed no conflicts of interest. among older adults ( $\geq 65$ y). ${ }^{1}$ In South Korea, the prevalence is estimated to be $13.5 \%$ among adults $40 \mathrm{y}$ and older and $31.5 \%$ among older adults ( $\geq 65$ y) (http://www. index.go.kr/egams/stts/jsp/potal/stts/PO_STTS_IdxMain. jsp?idx_cd=1012, Accessed September 28, 2014). Therefore, COPD is an important health problem that causes social and economic burdens. ${ }^{2,3}$

COPD is a progressive and debilitating respiratory disease, characterized by breathing difficulty and irreversible lung air flow limitations due to inflammation of the lower airway. COPD patients experience various physical and

\footnotetext{
Correspondence: Sung Reul Kim RN PhD, College of Nursing, Chonbuk National University, 567 Baekje-daero, Deokjin-gu, Jeonju-si, Jeollabuk-do 54899, Republic of Korea. E-mail: srkim@jbnu.ac.kr.
}

DOI: $10.4187 /$ respcare. 05374 
psychological symptoms such as dyspnea, fatigue, sleep disturbance, and depression. ${ }^{1,2}$ Dyspnea is a major typical symptom, and $64.2 \%$ of COPD patients report that shortness of breath impairs their quality of life (QOL). ${ }^{1,4}$ Approximately $55 \%$ of patients with COPD suffer from fatigue, ${ }^{5}$ and $15-65 \%$ of COPD patients have anxiety and/or depression. ${ }^{6,7}$ COPD patients with depression, anxiety, and fatigue reported a poor QOL..$^{2,8-10}$ In addition, approximately $72 \%$ of patients had at least one sleep complaint, and $50 \%$ had one or more sleep complaints $>3$ times a week. ${ }^{11}$ COPD patients with sleep disturbance had worse QOL, and sleep disturbance was related to depression, anxiety, and fatigue. ${ }^{4}$ Dry mouth related with use of medication and oxygen is a prevalent symptom ${ }^{5}$ and can affect physical, social, and psychological QOL. ${ }^{12,13}$ Moreover, decreased physical function may influence symptom aggravation, mortality, or QOL in COPD patients ${ }^{3,14,15}$ and is related to dyspnea, anxiety, depression, and fatigue symptoms.

While some COPD patients may experience only a single symptom, most patients experience multiple symptoms concurrently. ${ }^{5}$ Previous studies on symptoms in COPD have focused mainly on single or isolated symptoms and related factors. Although this approach has led to a better understanding of each symptom, it has major limitations because most COPD patients have multiple and concurrent symptoms. Additionally, it has been reported that interventions that consider various concurrent symptoms are more effective than independent interventions for each symptom. ${ }^{16}$

A symptom cluster has been defined as a group of two or more symptoms that occur concurrently and are interrelated. ${ }^{17}$ Each symptom in the cluster is independent but strongly interrelated, and one symptom can affect another symptom through its effect on a third symptom. ${ }^{17-20}$ In addition, symptom clusters negatively affect QOL. ${ }^{19,20}$ Due to the incurable nature of COPD, the treatment goals are to control symptoms, reduce exacerbation of symptoms, and improve QOL. ${ }^{2}$ Thus, health professionals should assess symptoms and identify their effects on QOL in COPD patients. In this respect, it is essential to investigate the complex effects of simultaneously occurring symptoms for successful symptom management and improvement of QOL in COPD patients. Although studies of symptom clusters in COPD have been conducted, ${ }^{21,22}$ relationships among symptom clusters and clinical characteristics, and the effects of symptom clusters on QOL, are rarely reported. Therefore, we performed this study to identify symptom clusters of COPD, to investigate the relationship between symptom clusters and clinical characteristics, and to explore the effects of symptom clusters on QOL in COPD patients.

\section{QUICK LOOK}

\section{Current knowledge}

Although patients with COPD experience and suffer from various physical and psychological symptoms concurrently, previous studies examining symptoms in COPD have focused mainly on single or isolated symptoms and related factors. Recently, studies have begun to investigate symptom clusters in COPD, and it has been suggested that patients with COPD may have specific patterns of symptom clusters.

\section{What this paper contributes to our knowledge}

Three symptom clusters were identified in subjects with COPD: respiratory-functional cluster, mood cluster, and fatigue-sleep cluster. The symptom clusters were differed significantly depending on age, educational level, and monthly income, and had a negative impact on quality of life in subjects with COPD.

\section{Methods}

\section{Study Design and Subjects}

A descriptive cross-sectional design was used. A convenience sample was recruited from the out-patient pulmonary medicine clinic of a university hospital in South Korea between November and December 2014. Inclusion criteria for our study were (1) COPD as a primary diagnosis confirmed by a pulmonologist according to the ICD10; (2) $\mathrm{FEV}_{1} / \mathrm{FVC} \leq 70 \%$ on pulmonary function test; (3) $\geq 20 \mathrm{y}$; (4) no past history of other major health problems that could potentially influence the symptoms and QOL, such as active cancer and/or chronic renal disease. We also excluded patients with concurrent asthma, tuberculosis, or other respiratory diseases.

A total of 130 subjects with COPD participated in our study. All subjects agreed to a face-to-face interview using structured questionnaires. Data were collected by 2 research assistants, who provided assistance with the subject questionnaires if needed. After the interview process, we also reviewed the medical records of the subjects. The Institutional Review Board approved this study, and all subjects were required to provide informed consent, in compliance with Institutional Review Board regulations. The subjects were given the option to voluntarily withdraw their informed consent at any point, and their personal data were kept strictly confidential throughout the study. 


\section{Clinical Measurement}

\section{Dyspnea}

Dyspnea was measured using the Borg scale, ${ }^{23}$ a oneitem tool to measure subjective respiratory difficulty. The intensity of dyspnea was scored, ranging from 0 points (no dyspnea) to 10 points (the most severe dyspnea).

\section{Fatigue}

Fatigue was measured using the Korean version of Functional Assessment of Chronic Illness Therapy-Fatigue. ${ }^{24}$ The reliability and validity have been validated in Korean subjects. ${ }^{25,26}$ The Korean version of this assessment consists of 13 questions, and each item is measured on a 4-point Likert scale. Higher scores indicate greater fatigue. Cronbach alpha for the scale was 0.930 .95 when developed $^{24}$ and was 0.89 in our study.

\section{Depression}

Depression was measured using the Beck Depression Inventory, which is one of the most commonly used tools for assessing depression. ${ }^{27-29}$ Its reliability and validity have been validated in Korean patients. ${ }^{29,30}$ The Beck Depression Inventory includes 21 questions, and each item is measured on a 4-point Likert scale. Scores range from 0 to 63, and higher scores indicate more severe depression. Cronbach alpha for the scale was 0.86 when developed ${ }^{27}$ and 0.82 in this study.

\section{Anxiety}

The Korean version of the Spielberger Anxiety Inventory was used to measure anxiety. ${ }^{31,32}$ This is a well-established scale that has been extensively used in research and clinical practice. ${ }^{33,34}$ The Spielberger Anxiety Inventory includes 20 questions, and the scores range from 20 to 80 . Higher scores indicate greater anxiety. Cronbach alpha for the scale was 0.86 when developed ${ }^{32}$ and 0.91 in our study.

\section{Sleep Disturbance}

Sleep disturbance was measured using the Korean Sleep Scale A, which is one of the commonly used tools for sleep disturbance among Koreans. ${ }^{35}$ The scale consists of 15 questions, and each item is measured on a 4-point Likert scale. Lower scores indicate greater sleep disturbance. Cronbach alpha for the scale was 0.75 when developed $^{35}$ and 0.90 in this study.

\section{Dry Mouth}

Dry mouth was measured with the visual analog scale. The intensity of dry mouth was scored, ranging from 0 (no dry mouth) to 10 (the most severe dry mouth).

\section{Physical Function}

The physical function was measured with the Karnofsky Performance Scale. ${ }^{36}$ This scale is widely used to quantify the physical functioning of patients. ${ }^{37}$ The tool has 11 levels, ranging from 0 (dead) to 100 (normal function).

\section{Quality of Life}

QOL was measured by the Korean version of the Clinical COPD Questionnaire with the permission of the developer. ${ }^{38}$ The questionnaire consists of 10 items with three domains: symptom (4 items), functional state (4 items), and mental state (2 items). Each item is measured on a 6-point Likert scale, and higher scores indicate poorer QOL. Cronbach alpha for this scale was 0.91 , and the Cronbach alphas of subscales were 0.78 for symptom, 0.89 for functional state, and 0.80 for mental state when validated. ${ }^{39}$ In this study, Cronbach alpha for this scale was 0.87 , and the Cronbach alphas of subscales were 0.87 for symptom, 0.82 for functional state, and 0.53 for mental state.

\section{Demographic and Clinical Characteristics of Participants}

Demographic characteristics of the subjects were age, sex, marital status, educational level, and monthly income. Clinical characteristics were duration of COPD, severity of air flow limitation, oxygen therapy, use of bronchodilator, and smoking status (current smoker, ex-smoker, or non-smoker). In addition, we reviewed chest x-ray or high-resolution computed tomography findings within 2 months. The severity of air flow limitation was categorized according to the Global Initiative for Chronic Obstructive Lung Disease (GOLD) grading system as follows: GOLD 1 mild $\left(\mathrm{FEV}_{1} 80 \% \geq\right.$ predicted), GOLD 2 moderate $\left(50 \leq \mathrm{FEV}_{1} \%<80 \%\right.$ predicted), GOLD 3 severe $\left(30 \leq \mathrm{FEV}_{1} \%<50 \%\right.$ predicted), and GOLD 4 very severe $\left(\mathrm{FEV}_{1} \%<30 \%\right.$ predicted $) .^{2}$

\section{Statistical Analyses}

Statistical analysis was performed with SPSS version 21.0 (IBM SPSS Statistics, SPSS, Chicago, Illinois). All data were expressed as percentage, median (interquartile range [IQR]), or range. To ensure the adequacy of data for factor analysis, we examined inter-item correlation coefficients by Spearman rank correlation. Next, a principal 
Symptom Clusters AND QOL IN COPD

Table 1. Demographic and Clinical Characteristics of COPD Subjects

\begin{tabular}{|c|c|c|c|}
\hline Characteristics & Categories & $n(\%)$ & Mean \pm SD \\
\hline \multirow[t]{2}{*}{ Gender } & Male & $112(86.2)$ & \\
\hline & Female & $18(13.8)$ & \\
\hline \multirow[t]{4}{*}{ Age, y } & $40 \sim 49$ & $3(2.3)$ & $69.5 \pm 8.7$ \\
\hline & $50 \sim 59$ & $14(10.8)$ & \\
\hline & $60 \sim 69$ & $41(31.5)$ & \\
\hline & $\geq 70$ & $72(55.4)$ & \\
\hline \multirow[t]{2}{*}{ Marital status } & Married & $108(83.1)$ & \\
\hline & Not married & $22(16.9)$ & \\
\hline \multirow[t]{5}{*}{ Education level } & Uneducated & $18(13.8)$ & \\
\hline & Elementary school & $39(30.0)$ & \\
\hline & Middle school & $28(21.5)$ & \\
\hline & High school & $30(23.1)$ & \\
\hline & $\geq$ College & $15(11.5)$ & \\
\hline \multirow{3}{*}{$\begin{array}{l}\text { Monthly income } \\
\text { (USD 8.78) }\end{array}$} & $<100$ & $72(55.4)$ & $118.9 \pm 113.0$ \\
\hline & $\leq 100 \sim 300<$ & $39(30.0)$ & \\
\hline & $\geq 300$ & $19(14.6)$ & \\
\hline \multirow{4}{*}{ Disease duration, $\mathrm{y}$} & $\leq 1$ & $16(12.3)$ & $6.3 \pm 4.6$ \\
\hline & $<1 \sim 5 \leq$ & $50(38.5)$ & \\
\hline & $<5 \sim 10 \leq$ & $41(31.5)$ & \\
\hline & $>10$ & $23(17.7)$ & \\
\hline \multirow[t]{4}{*}{ GOLD stage } & 1 & $5(3.8)$ & \\
\hline & 2 & $36(27.7)$ & \\
\hline & 3 & $68(52.3)$ & \\
\hline & 4 & $21(16.2)$ & \\
\hline \multirow[t]{2}{*}{ Oxygen therapy } & No & $119(91.5)$ & \\
\hline & Yes & $11(8.5)$ & \\
\hline \multirow[t]{2}{*}{ Bronchodilator } & No & $12(9.2)$ & \\
\hline & Yes & $118(90.8)$ & \\
\hline \multirow[t]{3}{*}{ Smoking } & Current smoker & $16(12.3)$ & \\
\hline & Ex-smoker & $85(65.4)$ & \\
\hline & Non smoker & $29(22.3)$ & \\
\hline
\end{tabular}

component analysis with varimax rotation was carried out to examine the existence of a relationship between symptoms. In addition, the Kaiser-Meyer-Olkin measure and the Bartlett test of sphericity were determined to confirm the adequacy of data for factor analysis. If the value of the Kaiser-Meyer-Olkin measure is $\geq 0.50$ and Bartlett test of sphericity is $\leq 0.05$, the data are adequate for factor analysis. ${ }^{40}$ Cronbach alpha was used to estimate the internal consistency and reliability of the derived clusters. To determine subgroups of symptom clusters, we used Kmeans cluster analysis. Cluster analysis is a grouping method that suggests the number of groups into which a set of samples can be classified, with the similarity measure calculated by the squared Euclidean distance. Subject subgroups were stratified on the basis of the average linkages between groups and the distance between factor loadings of respondents, which was calculated using squared
Table 2. Scores of Symptoms and Quality of Life in COPD Subjects

\begin{tabular}{lcc}
\hline \hline \multicolumn{1}{c}{ Variables } & Median (IQR) & Range \\
\hline Symptoms & & \\
$\quad$ Dyspnea & $3.0(1.0-4.0)$ & $0-8$ \\
Fatigue & $42.0(28.0-48.0)$ & $12-52$ \\
Depression & $8.0(4.0-11.0)$ & $0-28$ \\
Anxiety & $35.0(29.0-48.0)$ & $21-65$ \\
Sleep disorder & $26.5(20.0-35.0)$ & $16-58$ \\
Dry mouth & $3.0(0.0-5.0)$ & $0-10$ \\
Physical functional status & $80.0(70.0-90.0)$ & $50-100$ \\
Quality of life & $2.0(1.2-2.7)$ & $0.1-4.3$ \\
Symptom & $2.0(1.25-2.75)$ & $0-4.8$ \\
Functional state & $1.75(1.0-2.5)$ & $0-5.8$ \\
Mental state & $2.5(1.5-3.0)$ & $0-6.0$ \\
& & \\
$N=130$ & & \\
IQR $=$ interquartile range & & \\
\hline
\end{tabular}

Euclidian distance as a measure of similarity. The subject subgroups were compared in relation to demographic and clinical characteristics, and QOL scores were compared using chi-square test, $t$ test, and Mann-Whitney $\mathrm{U}$ test. We also used the Kolmogorov-Smirnov test to analyze the normality of the variables. A 2-tailed $P<.05$ was considered statistically significant.

\section{Results}

\section{Characteristics of Subjects}

The demographic and clinical characteristics of subjects are summarized in Table 1. Most subjects (86.2\%) were men, and the mean age was $69.5 \pm 8.7 \mathrm{y}$ (range $45-85 \mathrm{y}$ ). The mean disease duration was $6.3 \pm 4.6$ y (range $1-26$ y), and the mean predicted $\mathrm{FEV}_{1}$ was $60.9 \pm 18.6 \%$. Approximately $52.3 \%$ of subjects were categorized as GOLD 3 (severe), whereas $27.7 \%$ were categorized as GOLD 2. About $8.5 \%$ of subjects received oxygen therapy, and $90.8 \%$ used a bronchodilator. Of 130 subjects, 94 had a chest x-ray and 28 had high-resolution computed tomography. In chest $\mathrm{x}$-ray or high-resolution computed tomography findings, there were no recent changes in COPD and no other disease findings.

\section{Symptom and QOL in COPD}

The median scores of dyspnea, fatigue, depression, anxiety, sleep disturbance, dry mouth, physical functional status, and QOL are summarized in Table 2. The median (IQR) scores of dyspnea and fatigue were $3.0(1.0-4.0)$ and 42.0 (28.0-48.0), respectively. The median (IQR) scores for depression, anxiety, sleep disturbance, dry mouth, and physical functional status were 8.0 (4.0-11.0), 35.0 
Table 3. Symptom Clusters of COPD Subjects

\begin{tabular}{|c|c|c|c|}
\hline \multirow[b]{2}{*}{ Symptom } & \multicolumn{3}{|c|}{ Factor Loadings } \\
\hline & $\begin{array}{l}\text { Respiratory- } \\
\text { Function } \\
\text { Cluster } \\
\text { (Symptom } \\
\text { Cluster 1) }\end{array}$ & $\begin{array}{l}\text { Mood Cluster } \\
\text { (Symptom } \\
\text { Cluster 2) }\end{array}$ & $\begin{array}{c}\text { Fatigue-Sleep } \\
\text { Cluster } \\
\text { (Symptom } \\
\text { Cluster 3) }\end{array}$ \\
\hline Dyspnea & 0.83 & & \\
\hline Physical functional status & 0.71 & & \\
\hline Dry mouth & 0.70 & & \\
\hline Anxiety & & 0.92 & \\
\hline Depression & & 0.81 & \\
\hline Sleep disorder & & & 0.89 \\
\hline Fatigue & & & 0.74 \\
\hline Eigenvalue & 2.78 & 1.21 & 1.00 \\
\hline Explained variance & 1.86 & 1.66 & 1.47 \\
\hline Explained \% & 39.71 & 17.28 & 14.30 \\
\hline Cumulative $\%$ & 39.7 & 57.0 & 71.3 \\
\hline Kaiser-Meyer-Olkin & & 0.65 & \\
\hline Bartlett sphericity test & & $<.001$ & \\
\hline$N=130$ & & & \\
\hline
\end{tabular}

(29.0-48.0), 26.5 (20.0-35.0), $3.0(0.0-5.0)$, and 80.0 (70.0-90.0), respectively. In addition, the median (IQR) total QOL, symptom, functional state, and mental state domain scores were $2.0(1.2-2.7), 2.0$ (1.25-2.75), 1.75 $(1.0-2.5)$, and $2.5(1.5-3.0)$, respectively.

\section{Symptom Clusters in COPD}

The Spearman rank correlation coefficient value was $>.30$ for all of the variables, indicating the adequacy of data for factor analysis. Principal component analysis extracted components with Eigenvalues $>1.0$. In this study, the KaiserMeyer-Olkin measure was 0.645 , and the Bartlett test of sphericity was $<0.001$.

Three symptom clusters were identified, and they accounted for $71.3 \%$ of total variance (Table 3 ). Symptom cluster 1 (respiratory-function cluster) consisted of dyspnea, physical functional status, and dry mouth. The Eigenvalue of symptom cluster 1 was 2.779 , and symptom cluster 1 accounted for $39.7 \%$ of the total variance. Symptom cluster 2 (mood cluster) consisted of depression and anxiety and accounted for $17.3 \%$ of the total variance. Symptom cluster 3 (fatigue-sleep cluster) consisted of fatigue and sleep disturbance and accounted for $14.3 \%$ of the total variance. The Eigenvalues of symptom clusters 2 and 3 were 1.209 and 1.001 , respectively.

\section{Comparison of Clinical Characteristics and QOL According to Symptom Cluster}

Based on the 3 symptom clusters, we identified 2 subject subgroups by cluster analysis to identify symptom clusters according to clinical characteristics and the relationship with QOL. The group with the higher clusteranalysis score was called the high-symptom group, and the group with lower cluster-analysis score was called the lowsymptom group. In the respiratory-function cluster, $38.5 \%$ of participants were classified as belonging to the high-symptom group, and $61.5 \%$ were classified in the low-symptom group. In the mood cluster, $33.8 \%$ of participants were classified as belonging to the high-symptom group, and $66.2 \%$ were classified in the low-symptom group. In the fatiguesleep cluster, $33.8 \%$ of subjects were classified in the highsymptom group, with $66.2 \%$ in the low-symptom group.

The demographics, clinical characteristics, and QOL between these 2 subgroups are presented in Table 4 according to symptom cluster. In the respiratory-function cluster, the age of the subjects in the high-symptom group was significantly higher than subjects in the low-symptom group $(P=.007)$. Monthly income was significantly lower in the high-symptom group compared to the low-symptom group $(P=.003)$. The high-symptom group within the respiratory-function cluster had significantly poorer QOL in total, symptom, and functional state domains $(P=.007, P=.004$, and $P=.005$, respectively $)$, with the exception of the mental state domain $(P=.46)$. In the mood cluster, demographic and clinical characteristics were not significantly related with symptom cluster. However, subjects in the high-symptom group within the mood cluster had significantly poorer QOL in total $(P=.001)$ and in all domains $(P=.008, P=.003$, and $P<.001$, respectively) than subjects in the low-symptom group. In the fatigue-sleep cluster, subjects in the high-symptom group were significantly older than subjects in the lowsymptom group $(P=.049)$. Educational level was significantly lower in the high-symptom group compared to the low-symptom group $(P=.008)$. Monthly income was significantly lower in the high-symptom group compared to the low-symptom group $(P=.002)$. The high-symptom group within the fatigue-sleep cluster had significantly poorer QOL in total $(P<.001)$ and in all domains $(P=.003, P<.001$, and $P=.001$, respectively) than the low-symptom group.

\section{Discussion}

Our study included dyspnea, depression, anxiety, fatigue, sleep disturbance, dry mouth, and decreased physical function as the major symptoms in COPD based on literature review, and these symptoms were categorized into symptom clusters. This study identified symptom clusters in COPD subjects, the relationship between these clusters and clinical characteristics, and the negative effects of each cluster on QOL. Our results indicate that approaches and interventions based on symptom cluster may be more effective for improvement of symptom management and QOL in COPD subjects. 
Table 4. Comparison of Clinical Characteristics and Quality of Life Between Higher-Symptom and Lower-Symptom Groups

\begin{tabular}{|c|c|c|c|c|c|c|c|c|c|}
\hline \multirow{2}{*}{ Characteristics } & \multicolumn{3}{|c|}{$\begin{array}{l}\text { Respiratory-Function Cluster } \\
\text { (Symptom Cluster 1) }\end{array}$} & \multicolumn{3}{|c|}{$\begin{array}{c}\text { Mood Cluster } \\
\text { (Symptom Cluster 2) }\end{array}$} & \multicolumn{3}{|c|}{$\begin{array}{l}\text { Fatigue-Sleep Cluster } \\
\text { (Symptom Cluster 3) }\end{array}$} \\
\hline & $\begin{array}{l}\text { Higher-Symptom } \\
\text { Group }\end{array}$ & $\begin{array}{l}\text { Lower-Symptom } \\
\text { Group }\end{array}$ & $P$ & $\begin{array}{l}\text { Higher-Symptom } \\
\text { Group }\end{array}$ & $\begin{array}{l}\text { Lower-Symptom } \\
\text { Group }\end{array}$ & $P$ & $\begin{array}{l}\text { Higher-Symptom } \\
\text { Group }\end{array}$ & $\begin{array}{l}\text { Lower-Symptom } \\
\text { Group }\end{array}$ & $P$ \\
\hline \multicolumn{10}{|l|}{ Gender, $n(\%)$} \\
\hline Male & $44(88.0)$ & $68(85.0)$ & .63 & $36(81.8)$ & $76(88.4)$ & .31 & $38(86.4)$ & $74(86.0)$ & .96 \\
\hline Female & $6(12.0)$ & $12(15.0)$ & & $8(18.2)$ & $10(11.6)$ & & $6(13.6)$ & $12(14.0)$ & \\
\hline Age, $y$, mean $\pm S D$ & $72.1 \pm 9.6$ & $67.8 \pm 7.8$ & .007 & $67.9 \pm 9.3$ & $7.3 \pm 8.4$ & .13 & $71.6 \pm 8.2$ & $68.4 \pm 8.8$ & .049 \\
\hline \multicolumn{10}{|l|}{ Marital status, $n(\%)$} \\
\hline Married & $40(80.0)$ & $68(85.0)$ & .46 & $36(81.8)$ & $72(83.7)$ & .78 & $36(81.8)$ & $72(83.7)$ & .78 \\
\hline Not married & $10(8.5)$ & $12(15.0)$ & & $8(18.2)$ & $14(16.3)$ & & $8(18.2)$ & $14(16.3)$ & \\
\hline \multicolumn{10}{|l|}{ Education level, $n(\%)$} \\
\hline Uneducated & $8(16.0)$ & $10(12.5)$ & .26 & $6(13.6)$ & $12(14.0)$ & .64 & $6(13.6)$ & $12(14.0)$ & .008 \\
\hline Elementary school & $20(40.0)$ & $19(23.8)$ & & $15(34.1)$ & $24(27.9)$ & & $22(50.0)$ & $17(19.8)$ & \\
\hline Middle school & $9(18.0)$ & $19(23.8)$ & & $8(18.2)$ & $20(23.3)$ & & $6(13.6)$ & $22(25.6)$ & \\
\hline High school & $9(18.0)$ & $21(26.3)$ & & $12(27.3)$ & $18(2.9)$ & & $6(13.6)$ & $24(27.9)$ & \\
\hline$\geq$ College & $4(8.0)$ & $11(13.8)$ & & $3(6.8)$ & $12(14.0)$ & & $4(9.1)$ & $11(12.8)$ & \\
\hline $\begin{array}{l}\text { Monthly income (USD 8.78), } \\
\text { mean } \pm \text { SD }\end{array}$ & $84.8 \pm 84.6$ & $140.2 \pm 123.3$ & .003 & $104.9 \pm 89.0$ & $126.1 \pm 123.3$ & .26 & $81.9 \pm 82.8$ & $137.8 \pm 121.8$ & .002 \\
\hline Disease duration, y & 6.26 & 6.35 & .91 & 6.50 & 6.22 & .65 & 6.89 & 6.02 & .063 \\
\hline Predicted $\mathrm{FEV}_{1}, \%$ & 53.34 & 56.76 & .53 & 56.98 & 54.67 & .34 & 54.25 & 56.06 & .55 \\
\hline \multicolumn{10}{|l|}{ GOLD stage } \\
\hline 1 & $2(4.0)$ & $3(3.8)$ & .96 & $0(.0)$ & $5(5.8)$ & .20 & $2(4.5)$ & $3(3.5)$ & .45 \\
\hline 2 & $14(28.0)$ & $22(27.5)$ & & $16(36.4)$ & $20(23.3)$ & & $10(22.7)$ & $26(30.2)$ & \\
\hline 3 & $27(54.0)$ & $41(51.3)$ & & $21(47.7)$ & $47(54.7)$ & & $27(61.4)$ & $41(47.7)$ & \\
\hline 4 & $7(14.0)$ & $14(17.5)$ & & $7(15.9)$ & $14(16.3)$ & & $5(11.4)$ & $16(18.6)$ & \\
\hline \multicolumn{10}{|l|}{ Oxygen therapy, $n(\%)$} \\
\hline No & $47(94.0)$ & $72(90.0)$ & .43 & $40(9.9)$ & $79(91.9)$ & .85 & $40(90.9)$ & 79 (91.9) & .85 \\
\hline Yes & $3(6.0)$ & $8(10.0)$ & & $4(9.1)$ & $7(8.1)$ & & $4(9.1)$ & $7(8.1)$ & \\
\hline \multicolumn{10}{|l|}{ Bronchodilator, $n(\%)$} \\
\hline No & $4(8.0)$ & $8(10.0)$ & .70 & $4(9.1)$ & $8(9.3)$ & .97 & $3(6.8)$ & $9(10.5)$ & .50 \\
\hline Yes & $46(92.0)$ & $72(90.0)$ & & $40(9.9)$ & $78(9.7)$ & & $41(93.2)$ & $77(89.5)$ & \\
\hline \multicolumn{10}{|l|}{ Smoking, $n(\%)$} \\
\hline Current smoker & $8(16.0)$ & $8(10.0)$ & .45 & $5(11.4)$ & $11(12.8)$ & .86 & $7(15.9)$ & $9(10.5)$ & .66 \\
\hline Ex-smoker & $33(66.0)$ & $52(65.0)$ & & $28(63.6)$ & $57(66.3)$ & & $28(63.6)$ & $57(66.3)$ & \\
\hline Non smoker & $9(18.0)$ & $20(25.0)$ & & $11(25.0)$ & $18(2.9)$ & & $9(20.5)$ & $20(23.3)$ & \\
\hline Quality of life, mean \pm SD & $2.3 \pm 1.0$ & $1.8 \pm 1.0$ & .007 & $2.4 \pm 1.0$ & $1.8 \pm 1.0$ & .001 & $2.4 \pm 1.0$ & $1.8 \pm 1.0$ & $<.001$ \\
\hline Symptom & $2.3 \pm 1.0$ & $1.8 \pm 1.0$ & .004 & $2.3 \pm 1.0$ & $1.8 \pm 1.0$ & .008 & $2.4 \pm 1.0$ & $1.8 \pm 1.0$ & .003 \\
\hline Functional state & $2.1 \pm 1.0$ & $1.6 \pm 1.1$ & .005 & $2.2 \pm 1.1$ & $1.6 \pm 1.0$ & .003 & $2.3 \pm 1.2$ & $1.6 \pm 1.0$ & $<.001$ \\
\hline Mental state & $2.4 \pm 1.3$ & $2.2 \pm 1.4$ & .46 & $2.8 \pm 1.2$ & $2.0 \pm 1.3$ & $<.001$ & $2.8 \pm 1.4$ & $2.0 \pm 1.3$ & .001 \\
\hline
\end{tabular}

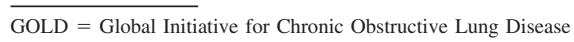

Our results showed that the median QOL score was 2.0. This is higher than the QOL score for healthy smokers and lower than that for COPD subjects reported in previous studies. The median QOL score with IQR was $0.8(0.1-$ 3.3 ), and the scores for symptom, functional state, and mental state was $1.5(0.3-3.5), 0.8(0.0-3.8), 0.0(0.0-3.0)$ in healthy smokers, respectively. ${ }^{38}$ The mean QOL score for COPD subjects was reported as 1.8-3.1..$^{39,41}$ The lower QOL score in this study in comparison to previous studies may be due to the COPD severity of our subjects. Van der Molen et $\mathrm{al}^{38}$ reported that Clinical COPD Questionnaire score and predicted $\mathrm{FEV}_{1} \%$ were significantly correlated, with a score of 1.8 in GOLD 1, 2.0 in GOLD 2, 3.1 in GOLD 3, and 2.9 in GOLD 4. In our study, 31.5\% of subjects were categorized as GOLD 1 or 2 , whereas $16.2 \%$ were GOLD 4. Therefore, further research is needed on
QOL in cases of COPD, including subjects with varying degrees of severity.

In addition, the score for mental state QOL was higher than scores for symptom, functional state, and total domain QOL in this study. Canavan et al reported that the mean scores of symptoms, functional state, mental state, and total QOL were $2.2 \pm 1.1,1.9 \pm 1.3,1.8 \pm 1.5$ and $2.5 \pm 1.1$, respectively. ${ }^{39}$ This indicates that COPD patients in Korea have poor QOL in the mental status domain. Therefore, health professionals must pay attention to mental QOL in Korean COPD subjects.

Interestingly, this study showed that all subjects have anxiety, although the severity of anxiety differed among subjects. This result is consistent with a previous study ${ }^{42}$ that reported that COPD patients experience anxiety due to concerns with recurrent dyspnea, after the first occurrence 
of shortness breath. This result suggests that anxiety symptoms should be carefully examined and managed.

Among the 3 symptom clusters identified in this study, the respiratory-function cluster consisted of dyspnea, physical functional status, and dry mouth. This finding is consistent with a recent study finding that subjects with severe air-flow limitation concurrently experienced dyspnea, decreased physical function, and dry mouth. ${ }^{5}$ The mood cluster consisted of depression and anxiety, and many studies have reported that subjects with COPD have concurrent depression and anxiety. ${ }^{9,43,44}$ The fatigue-sleep cluster consisted of fatigue and sleep disturbance, similar to symptom clusters in breast cancer patients. ${ }^{45}$

Understanding the relationships between symptom clusters and clinical characteristics can be beneficial for several reasons. First, it can contribute to identification of clinical characteristics according to symptom cluster. Second, it can help select target groups for symptom management, thereby providing effective patient management. Third, symptom clusters may help identify significant symptoms that patients experience but do not report. Therefore, investigation of the complex effect of simultaneously occurring symptom clusters in COPD is essential for successful management of the disease and improvement of QOL in COPD patients. ${ }^{46-48}$

In this study, older age and lower monthly income were related with the higher respiratory-function cluster, whereas older age, lower monthly income, and lower educational level were related with higher fatigue-sleep cluster score. On the basis of this finding, older COPD patients and those with low monthly income should be carefully assessed for dyspnea, physical functional status, dry mouth, fatigue, and sleep disturbance. In addition, COPD patients with a low educational level should be monitored for fatigue and sleep disturbance.

In our study, mood cluster was not related to clinical characteristics. In previous studies, the relationships between mood cluster and clinical characteristics have been inconsistently reported. According to a systematic review on the prevalence of depression in COPD, increasing severity of COPD was associated with high prevalence of depression in two thirds of the selected studies, whereas the severity of COPD was not related with the prevalence of depression in one third of the studies. ${ }^{6}$ Depression and anxiety were not related with clinical characteristics in our study; therefore, depression and anxiety of patients with COPD should be assessed and managed regardless of clinical characteristics.

GOLD stage, use of oxygen therapy and bronchodilator, and smoking status were not related with the respiratoryfunction cluster in our study. This finding suggests that objective dyspnea index for COPD severity is not always consistent with subjective perception. Kim et al ${ }^{49}$ reported that subjective dyspnea according to the Medical Research
Council Dyspnea Scale ${ }^{50}$ was not related with GOLD stage. In other words, COPD patients with severely decreased lung function may not complain of shortness of breath, whereas those with mildly decreased lung function may suffer from dyspnea. Therefore, both objective and subjective dyspnea of COPD patients should be managed.

Patients with COPD become more hypoxemic during sleep than when awake and even during exercise. ${ }^{51}$ Sleep disturbance may increase fatigue ${ }^{52}$; conversely, fatigue can cause poor quality of sleep. ${ }^{53}$ Similarly, it is well known that fatigue and sleep disturbance symptoms cluster in cancer patients, ${ }^{45,48}$ and cognitive-behavioral therapy, coping skill training, and meditation have been shown to have beneficial effects on both fatigue and sleep disturbance in cancer patients. ${ }^{45}$ Moreover, because progressive relaxation exercise is effective for fatigue and sleep disturbance in COPD, ${ }^{52}$ sleep disturbance and fatigue in COPD need to be assessed and managed together.

In our study, the high-symptom group in the mood and fatigue-sleep clusters had significantly poorer QOL in all domains. The high-symptom group in the respiratoryfunction cluster also had poorer QOL, except in the mental state domain. These findings suggest that depression, anxiety, fatigue, and sleep disturbance can affect all domains of QOL, while dyspnea, decreased physical function, and dry mouth can affect QOL associated with symptom and functional state in COPD.

This study has some limitations. First, the numbers of female subjects and subjects with GOLD 4 in this study were small. Second, this study was a descriptive, crosssectional study and did not identify longitudinal changes in symptom clusters associated with COPD. Third, while the Cronbach alpha for the QOL scale was good, the Cronbach alpha for the QOL scale mental state was low. Finally, because not all subjects underwent radiographic examinations such as x-ray or high-resolution computed tomography, we could not distinguish clearly between symptoms of COPD and symptoms associated with other lesions. Therefore, further studies are required to explore these issues.

\section{Conclusions}

Symptom clusters are related with clinical characteristics and have a negative impact on QOL in subjects with COPD. To enhance symptom management and QOL, approaches and interventions based on symptom cluster are more effective than independent intervention for each symptom. Understanding symptom clusters will increase successful symptom management, which may improve the QOL of COPD patients. 


\section{Symptom Clusters AND QOL IN COPD}

\section{REFERENCES}

1. Centers for Disease Control and Prevention (CDC). Chronic obstructive pulmonary disease among adults-United States, 2011. MMWR Morb Mortal Wkly Rep 2012;61(46):938-943.

2. Vogelmeier CF, Criner GJ, Martinez FJ, Anzueto A, Barnes PJ, Bourbeau J, et al. Global strategy for the diagnosis, management, and prevention of chronic obstructive lung disease: 2017 report. Respirology 2017;22(3):575-601.

3. Park SK, Meldrum CA, Larson JL. Subgroup analysis of symptoms and their effect on functioning, exercise capacity, and physical activity in patients with severe chronic obstructive pulmonary. Heart Lung 2013;42(6):465-472.

4. Borge CR, Wahl AK, Moum T. Association of breathlessness with multiple symptoms in chronic obstructive pulmonary disease. J Adv Nurs 2010;66(12):2688-2700.

5. Eckerblad J, Tödt K, Jakobsson P, Unosson M, Skargren E, Kentsson M, Theander K. Symptom burden in stable COPD patients with moderate or severe airflow limitation. Heart Lung 2014;43(4):351-357.

6. Matte DL, Pizzichini MM, Hoepers AT, Diaz AP, Karloh M, Dias M, Pizzichini E. Prevalence of depression in COPD: a systematic review and meta-analysis of controlled studies. Respir Med 2016; 117(1):154-161.

7. Kunik ME, Roundy K, Veazey C, Souchek J, Richardson P, Wray NP, Stanley MA. Surprisingly high prevalence of anxiety and depression in chronic breathing disorders. Chest 2005;127(4):1205-1211.

8. Antoniu SA, Ungureanu D. Measuring fatigue as a symptom in COPD: from descriptors and questionnaires to the importance of the problem. Chron Respir Dis 2015;12(3):179-188.

9. Iguchi A, Senjyu H, Hayashi Y, Kanada R, Iwai S, Honda S, et al. Relationship between depression in patients with COPD and the percent of predicted FEV1, BODE index, and health-related quality of life. Respir Care 2013;58(2):334-339.

10. Henoch I, Strang S, Löfdahl CG, Ekberg-Jansson A. Health-related quality of life in a nationwide cohort of patients with COPD related to other characteristics. Eur Clin Respir J 2016;3(1):31459.

11. Budhiraha R, Parthasarathy S, Budhiraja P, Habib MP, Wendel C, Quan SF. Insomnia in patients with COPD. Sleep 2012;35(3):369-375.

12. Cassolato SF, Turnbull RS. Xerostomia: clinical aspects and treatment. Gerodontology 2003;20(2):64-77.

13. Ekström M, Sundh J, Larsson K. Patient reported outcome measures in chronic obstructive pulmonary disease: which to use? Expert Rev Respir Med 2016;10(3):351-362.

14. Hartman JE, Boezen HM, de Greef MH, Bossenbroek L, ten Hacken $\mathrm{NH}$. Consequences of physical inactivity in chronic obstructive pulmonary disease. Expert Rev Respir Med 2010;4(6):735-745.

15. Dürr S, Zogg S, Miedinger D, Steveling EH, Maier S, Leuppi JD. Daily physical activity, functional capacity and quality of life in patients with COPD. COPD 2014;11(6):689-696.

16. Lenz ER, Pugh LC, Milligan RA, Gift A, Suppe F. The middle-range theory of unpleasant symptoms: an update. ANS Adv Nurs Sci 1997; 19(3):14-27.

17. Kim HJ, McGuire DB, Tulman L, Barsevick AM. Symptom clusters: concept analysis and clinical implications for cancer nursing. Cancer Nurs 2005;28(4):270-282.

18. Barsevick AM, Whitmer K, Nail LM, Beck SL, Dudley WN. Symptom cluster research: conceptual, design, measurement, and analysis issues. J Pain Symptom Manage 2006;31(1):85-95.

19. Ferreira KA, Kimura M, Teixeira MJ, Mendoza TR, da Nóbrega JC, Graziani SR, Takagaki TY. Impact of cancer-related symptom synergisms on health-related quality of life and performance status. J Pain Symptom Manage 2008;35(6):604-616.

20. Ryu E, Kim K, Cho MS, Kwon IG, Kim HS, Fu MR. Symptom clusters and quality of life in Korean patients with hepatocellular carcinoma. Cancer Nurs 2010;33(1):3-10.
21. Park SK, Larson JL. Symptoms cluster, healthcare use and mortality in patients with severe chronic obstructive pulmonary disease. J Clin Nurs 2014;23(17-18):2658-2671.

22. Park SK, Stotts NA, Douglas MK, Donesky-Cuenco D, CarrieriKohlman V. Symptoms and functional performance in Korean immigrants with asthma of chronic obstructive pulmonary disease. Heart Lung 2012;41(3):226-237.

23. Borg CA. Psychophysical bases of perceived exertion. Med Sci Sports Exerc 1982;14(5):377-381.

24. Yellen SB, Cella DF, Webster K, Blendowski C, Kaplan E. Measuring fatigue and other anemia-related symptoms with the Functional Assessment of Cancer Therapy (FACT) measurement system. J Pain Symptom Manage 1997;13(2):63-74.

25. Yoo S, Jung YS, Park JH, Kim HJ, Cho YK, Sohn CI, et al. Fatigue severity and factors associated with high fatigue levels in Korean patients with inflammatory bowel disease. Gut Liver 2014;8(2):148-153.

26. Oh PJ, Lee JR. Effect of cancer symptoms and fatigue on chemotherapy-related cognitive impairment and depression in people with gastrointestinal cancer. J Korean Acad Nurs 2016;46(3):420-430.

27. Beck AT, Ward CH, Mendelson M, Mock J, Erbaugh J. An inventory for measuring depression. Arch Gen Psychiatry 1961;4(6):561-571.

28. Lee YH, Song JY. A study of the reliability and the validity of the BDI, SDS, and MMPI-D scales. Korean J Clin Psychol 1991;10(1): 98-113.

29. Kil SY, Oh WO, Koo BJ, Suk MH. Relationship between depression and health-related quality of life in older Korean patients with chronic obstructive pulmonary disease. J Clin Nurs 2010;19(9-10):1307-1314.

30. Jo SA, Park MH, Jo I, Ryu SH, Han C. Usefulness of Beck Depression Inventory (BDI) in the Korean elderly population. Int J Geriatr Psychiatry 2007;22(3):218-223.

31. Spielberger CD, Gorshch RL, Lushene RE. Manual for the StateTrait Anxiety Inventory. Palo Alto, CA: Consultion Psychologist Press 1970.

32. Kim JT, Shin DK. A study based on the standardization of the STAI for Korea. New Med J 1978;21(11):69-75.

33. Ju HO, McElmurry BJ, Park CG, McCreary L, Kim M, Kim EJ. Anxiety and uncertainty in Korean mothers of children with febrile convulsion: cross-sectional survey. J Clin Nurs 2011;20(9-10):14901497.

34. Luo YY. Effects of written plus oral information vs. oral information alone on precolonoscopy anxiety. J Clin Nurs 2013;22(5-6):817-827.

35. Oh JJ, Song MS, Kim SM. Development and validation of Korean Sleep Scale A. J Korean Acad Nurs 1998;28(3):563-572.

36. Karnofsky DA, Burchenal JH. The clinical evaluation of chemotherapeutic agents in cancer. In McLeod CM, ed. The evaluation of chemotherapeutic agents. New York, NY: Columbia University Press 1949;191-205.

37. Nicoletti S, Porock D, Kristjanson LJ, Medigovich K, Pedler P, Smith M. Performance status assessment in home hospice patients using a modified form of the Karnofsky Performance Status Scale. J Palliat Med 2000;3(3):301-311.

38. van der Molen T, Willemse BW, Schokker S, ten Hacken NH, Postma DS, Juniper EF. Development, validity and responsiveness of the clinical COPD questionnaire. Health Qual Life Outcomes 2003;1(1):13.

39. Canavan JL, Dilaver D, Clark AL, Jones SE, Nolan CM, Kon SS, Man WD. Clinical COPD questionnaire in patients with chronic respiratory disease. Respirology 2014;19(7):1006-1012.

40. Lee HS, Lim JH. SPSS 20.0 Manual. Seoul: JybHyunJae Publishing Co., 2013.

41. Miravitlles M, García-Sidro P, Fernández-Nistal A, Buendía MJ, Espinosa de los Monteros MJ, Molina J. Course of COPD assessment test (CAT) and clinical COPD questionnaire (CCQ) scores during recovery from exacerbations of chronic obstructive pulmonary disease. Health Qual Life Outcomes 2013;11(1):147. 


\section{Symptom Clusters AND QOL IN COPD}

42. Kim SR, Kim YO, Kwon KM. Living as severe COPD patient: life of stepping on the thin ice. J Korean Acad Adult 2010;22(6):663-675.

43. Valenza MC, Valenza-Peña G, Torres-Sánchez I, González-Jiménez E, Conde-Valero A, Valenza-Demet G. Effectiveness of controlled breathing techniques on anxiety and depression in hospitalized patients with COPD: a randomized clinical trial. Respir Care 2014; 59(2):209-215.

44. Lou P, Chen P, Zhang P, Yu J, Wang Y, Chen N, et al. Effects of smoking, depression, and anxiety on mortality in COPD patients: a prospective study. Respir Care 2014;59(1):54-61.

45. Kwekkeboom KL, Cherwin CH, Lee JW, Wanta B. Mind-body treatments for the pain-fatigue-sleep disturbance symptom cluster in persons with cancer. J Pain Symptom Manage 2010;39(1):126-138.

46. Kim SR, So HY, Choi E, Kang JH, Kim HY, Chung SJ. Influencing effect of non-motor symptom clusters on quality of life in Parkinson's disease. J Neurol Sci 2014;347(1-2):310-315.

47. Miaskowski C, Cooer BA, Paul SM, Dodd M, Lee K, Aouixerat BE, et al. Subgroups of patients with cancer with different symptom experiences and quality-of-life outcomes: a cluster analysis. Oncol Nurs Forum 2006;33(5):E79-E89.
48. Kim SH, Lee R, Lee KS. Symptom clusters in patients with breast cancer. Korean J Adult Nurs 2009;21(6):705-717.

49. Kim EJ, Park JH, Yoon SJ, Lee SJ, Cha SI, Park JY, et al. Relationship between dyspnea and disease severity, quality of life, and social factor in patients with chronic obstructive pulmonary disease. Tuberc Respir Dis 2006;60(4):397-403.

50. Fletcher CM, Elmes PC, Fairbairn AS, Wood CH. The significance of respiratory symptoms and the diagnosis of chronic bronchitis in a working population. BMJ 1959;2(5147):257-266.

51. Mulloy E, McNicholas WT. Ventilation and gas exchange during sleep and exercise in severe COPD. Chest 1996;109(2):387-394.

52. Akgün Şahin Z, Dayapoğlu N. Effect of progressive relaxation exercises on fatigue and sleep quality in patients with chronic obstructive lung disease (COPD). Complement Ther Clin Pract 2015;21(4): 277-281.

53. Grossi G, Jeding K, Söderström M, Osika W, Levander M, Perski A. Self-reported sleep lengths $\geq 9$ hours among Swedish patients with stress-related exhaustion: associations with depression, quality of sleep and levels of fatigue. Nord J Psychiatry 2014;69(4): 292-299. 